\title{
Oocyte Cryopreservation during COVID-19 pandemic - Economic implications
}

\author{
Limor Dina Gonen* \\ Department of Economics and Business Administration, Ariel University, Israel \\ *Corresponding author: Limor Dina Gonen, Department of Economics and Business Administration, Ariel University, Israel \\ To Cite This Article: Limor Dina Gonen. Oocyte Cryopreservation during COVID-19 pandemic - Economic implications. Am J Biomed Sci \& Res. \\ 2021 - 13(1). AJBSR.MS.ID.001824. DOI: 10.34297/AJBSR.2021.13.001824.
}

Received: 海 May 05, 2021; Published: 笽 May 25, 2021

\section{Opinion}

The novel infectious Coronavirus disease-2019 (COVID-19), which was declared a pandemic on March 11th, 2020 by the World Health Organization (WHO) is turning into a global health disaster and causing radical changes to daily life as well as healthcare assessments.

To respond to the pandemic, the European Society of Human Reproduction and Embryology (ESHRE) released a statement on March 19th, 2020 advocating a cautious approach concerning planning a pregnancy so long as the pandemic lasts [1]. This has raised the issue oocyte/embryo cryopreservation and the benefits it can offer as an instrument of Assisted Reproductive Technology (ART) treatments [2-3] in uncertain times or natural disasters, including pandemics.

There is a low if even non-existent risk of genetic material (i.e., gametes, embryos, tissue) becoming infected by COVID-19 in the ART laboratory due to the strict insistence on protocol and guidelines that regulate handling procedures, including repeated washing, freezing, and storage. These precautions are in place to prevent sample contamination or cross contamination by pathogens, thus leading to dilution of possible viral contaminants and rendering them ineffective. Despite the absence of current date, the ESHRE hypothesized that there was minimal risk of infection of gametes and embryos because of the absence of COVID-19 receptors [4].

Oocyte/embryo cryopreservation holds out the prospect of successful pregnancy post-pandemic for women who cannot become pregnant at present due to pre-existing medical conditions with heightened risk of Covid-19 infection (i.e., kidney or liver disease, diabetes mellitus, hypertension, cardiological problems, and immunocompromised conditions, including oncology patients under treatment or suffering from AIDS). It also offers promise to women of advanced age and/or reduced ovary production [5]. It could offer hope that if the pandemic persists for many months or even years, these women will still have a chance of producing offspring. Cryopreservation facilitates planning of future pregnancies when the pandemic has ended to avoid the possibly serious problems of pregnancies complicated by COVID-19 [6-7].

There is no data that currently documents a heightened risk of severe illness in pregnant women compared with the general population [6,8-9], yet COVID-19 infection has been known to cause severe maternal morbidity requiring premature delivery and its risks to the neonate [8-10]. The adverse long-term effects of COVID-19 on infant health, especially when the mother is exposed in the first months of pregnancy, is likewise unknown as yet, so that there is an increased emphasis on avoiding pregnancy during the pandemic because of these concerns [1].

If during normal times, there are multiples aspects and factors to be considered - social, ethical, political, psychological, and economic - when approaching the issue of oocyte/embryo cryopreservation, these are of even greater import during a health disaster. The discourse concerning the social benefits of oocyte/ embryo/reproductive cell cryopreservation is crucial when weighing public funding for it.

The right to reproduce is generally regarded as a libertyright rather than a claim-right [11]. In the case of 'non-medical 'cryopreservation', i.e., social oocyte cryopreservation, this suggests that although women may choose to cryopreserve their oocyte, they cannot make a claim on society to financially support their choice [12]. The questions this raises are whether in emergency situations, oocyte cryopreservation serves the public interest and 
whether elective oocyte cryopreservation should be covered by public healthcare (or considered mandatory in insurance coverage) and be state funded.

Since oocyte cryopreservation is a complex and costly process [13-17], this issue is becoming more pressing in the face of an imminent economic crisis, for both private and public health services.

Because policy makers are called upon to incorporate values that best reflect the public's preferences in policy decisions that concern clinical, licensing, and reimbursement considerations, they must understand how the public rates various aspects of health care treatments. Health care policy must be accordingly designed and assessed in order to enhance the effectiveness of health care procedures [18-20].

Economists have defined two approaches to measure preference: revealed and stated [21]; both are grounded on the same theoretical basis. Revealed preferences are derived from observing actual market activities and can be identified by intricate econometric methods. Stated preferences are derived from surveys which are designed to allow researchers to control how the preferences are evoked.

\section{Methods to elicit fall into two categories:}

Methods that directly elicit the value assigned to an intervention (these include contingent valuation or WTP and Willingness-toAccept methods) [21-22] - intended to evaluate demand for a single good, or methods that employ rating, ranking, or choice (either individually or in combination) to quantify preferences for different attributes of an intervention (generally known as CA, discretechoice experiments, or stated-choice) - designed to study trade-offs between various attributes of a product and its effect on preference. to assign a monetary value to health benefits relating to a specific healthcare intervention, When the purpose is to elicit the patients' values and preferences toward various healthcare interventions as well as gauge the general public's attitude, researchers usually use the WTP [23], and it is also typically used to enable measuring the respondents' perception of the benefits in an overall assessment [24-29].

Health care studies have witnessed an upswing in the application of CA studies [30-32]. Using the CA method, one can derive partworth values for individual attributes from the total score given to a good or service that consists of two or more attributes, after ranking a set of values [33-36]. This method is particularly suited to quantifying preferences for commodities and services not traded on the market or when market choices are limited by legal constraints or regulatory mechanisms; this is relevant for health care services and products [37]. CA has been employed successfully to measure preferences for a broad range of health applications [20,32,38-42], although it may also be of use in many other fields other than health care. CA has come into increased use for learning people's preferences for health-related quality of life (health state) and to assess the outcomes of various health states reported by patients [43-44]. Licensing authorities have shown an interest in using CA to assess patients' willingness to take risks such as by undergoing pioneering treatments which offer improved efficacy [45]. CA offers a mechanism for facilitating decision making both for patient participation [46-47] and for shared decision making [48] as well as to understand clinical decision making [49] and how the various parties at interest valuate healthcare outcomes [50]. Besides valuating the relative importance of one or more attributes of a commodity or service, the CA method can be utilized to gauge how individuals tradeoff between the various attributes, i.e., to what extent the user is prepared to trade one unit of an attribute for another [51]. In a typical CA study, respondents are presented with scenarios comprised of the attributes of a commodity or service ranked at different levels of importance.

I suggest applying two techniques together to elicit preferences: WTP and CA. WTP is the maximum amount of money a person would be willing to spend or exchange for goods or a service, here, to improve their fertility chances [52]. WTP theory predicates that the amount of money a person is willing to spend for a particular benefit in healthcare indicates what value the person attributes to the benefit. CA is a useful tool in determining what value an individual assigns to specific benefits of a health product or service [37]. An analysis of how respondents specify their preferences for various components of the product or service can establish the utility, or implied value of particular attributes of the health treatment.

After the public utility and benefit from oocyte cryopreservation have been assessed, there should be an examination of the state authority's considerations with regard using the limited national medical budget to fund it. Based on the literature, medical interventions should be given state funding to the extent that the medical costs equal the social benefits they generate.

\section{References}

1. European Society of Human Reproduction and Embryology. News and Statements. Coronavirus Covid-19: ESHRE Statement on Pregnancy and Conception. https://www.eshre.eu/Press-Room/ESHRENews\#COVID19_April2

2. Rienzi L, Gracia C, Maggiulli R, LaBarbera AR, Kaser DJ, et al. (2017) embryo and blastocyst cryopreservation in ART: systematic review and meta-analysis comparing slow-freezing versus vitrification to produce evidence for the development of global guidance. Hum Reprod Update 23(2): 139-155.

3. Vigano P, Alteri A, Busnelli A, Vanni VS, Somigliana E (2020) Frozen IVF cycles to circumvent the hormonal storm on endometrium. Trends Endocrinol Metab 31: 296-307. 
4. Alteri A, Pisaturo V, Somigliana E, Viganò P (2020) Cryopreservation in reproductive medicine during the COVID-19 pandemic: rethinking policies and European safety regulations. Human Reproduction 35(12): 2650-2657.

5. Van Voorhis BJ (2007) Clinical practice. In vitro fertilization. N Engl J Med 356(4): 379-386

6. Chen L, Li Q, Zheng D, Jiang H, Wei Y, et al. (2020) Clinical characteristics of pregnant women with COVID-19 in Wuhan, China. N Engl J Med 382(25): e100.

7. Mullins E, Evans D, Viner RM, O’Brien P, Morris E (2020) Coronavirus in pregnancy and delivery: rapid review. Ultrasound Obstet Gynecol 55(5): 586-592.

8. Della Gatta AN, Rizzo R, Pilu G, Simonazzi G (2020) Coronavirus disease 2019 during pregnancy: a systematic review of reported cases. Am J Obstet Gynecol 223(1): 36-41.

9. Parazzini F, Bortolus R, Mauri PA, Favilli A, Gerli S, et al. (2020) Delivery in pregnant women infected with SARS-CoV-2: A fast review. Int J Gynaecol Obstet 150(1): 41-46.

10. Zaigham M, Andersson O (2020) Maternal and perinatal outcomes with COVID-19: A systematic review of 108 pregnancies. Acta Obstet Gynecol Scand 99(7): 823-829.

11. Shanner L (1995) The right to procreate: when rights claims have gone wrong. McGill Law J 40: 823-874.

12. Mertes H, Pennings G (2012) Elective oocyte cryopreservation: who should pay? Hum Reprod 27(1): 9-13.

13. Alteri A, Pisaturo V, Nogueira D, D’Angelo A (2019) Elective egg freezing without medical indications. Acta Obstet Gynecol Scand 98(5): 647-652.

14. Cassettari L, Mosca M, Mosca R, Rolando F, Costa M, et al. (2016) IVF cycle cost estimation using activity based costing and Monte Carlo simulation. Health Care Manag Sci 19: 20-30.

15. Le KD, Vuong LN, Ho TM, Dang VQ, Pham TD, et al. (2018) A costeffectiveness analysis of freeze-only or fresh embryo transfer in IVF of non-PCOS women. Hum Reprod 33(10): 1907-1914.

16. Papaleo E, Pagliardini L, Vanni VS, Delprato D, Rubino P, et al. (2017) A direct healthcare cost analysis of the cryopreserved versus fresh transfer policy at the blastocyst stage. Reprod Biomed Online 34(1): 19-26.

17. Somigliana E, Busnelli A, Vigano P, Vegetti W, Goisis A, et al. (2020) Is early initiation of infertility treatment justified in women over the age of 35 years? Reprod Biomed Online 40(3): 393-398.

18. Chong C, Chen I, Naglie C, (2007) Do clinical practice guidelines incorporate evidence on patient preferences? Med Decis Making 27: E63-E64.

19. Khrahn M, Naglie G (2008) The next step in guideline development. Incorporating patient preferences. JAMA 300(4): 436-438

20. Marshall DA, Johnson FR, Kulin NA, Ozdemir S, Walsh JME, et al. (2009) How do physician assessments of patient preferences for colorectal cancer screening tests differ from actual preferences? Comparison in Canada and the United States using a stated-choice survey. Health Econ 18(12): 1420-1439.

21. Bridges J, Onukwugha E, Johnson FR (2007) Patient preference methods-a patient centered evaluation paradigm. ISPOR Connections 13: 4-7.

22. Bridges J (2003) Stated-preference methods in health care evaluation: an emerging methodological paradigm in health economics. Appl Health Econ Health Policy 2(4): 213-224.

23. Ryan M, Scott DA, Reeves C, Bate A, van Teijlingen ER, et al. (2001) Eliciting public preferences for healthcare: a systematic review of techniques. Health Technol Assess 5(5): 1-186.
24. Olsen JA, Smith RD (2001) Theory versus practice: a review of 'willingness-to-pay' in health and health care. Health Econ 10(1): 39-52.

25. Herath G, Yang JC, Pattanayak S, Choe KA (2007) Good practices for estimating reliable willingness-to-pay values in the water supply and sanitation sector. Asian Development Bank. ERD Technical Note Series No 23 .

26. Lin PJ, Cangelosi M, Lee DW, Neumann PJ (2013) Willingness to pay for diagnostic technologies: a review of the contingent valuation literature. Value in Health 16(5), 797-805.

27. Basu R (2013) Willingness-to-pay to prevent Alzheimer's disease: a contingent valuation approach. Int J Health Care Finance Econ 13(3-4): 233-245.

28. Gardino SL, Sfekas A, Dranove D (2010) Anticipating Ovarian Tissue Cryopreservation in the Health-Care Marketplace: A Willingness to Pay Assessment. Cancer Treat Res 156: 363-370.

29. Palumbo A, De La Fuente P, Rodriguez M, Sanchez F, Martinez Salazar J, et al. (2011) Willingness to pay and conjoint analysis to determine women's preferences for ovarian stimulating hormones in the treatment of infertility in Spain. Hum. Reprod 26(7): 1790-1798.

30. Bridges JFP, Kinter ET, Kidane L, Heinzen RR, McCormick C (2008) Things are looking up since we started listening to patients: recent trends in the application of conjoint analysis in health 1970-2007. Patient 1(4):273282.

31. Ryan M, Gerard K (2003) Using discrete choice experiments to value health care programmes: current practice and future research reflections. Appl Health Econ Health Policy 2(1): 55-64.

32. Marshall DA, McGregor E, Currie G (2010) Measuring preferences for colorectal cancer (CRC) screening-what are the implications for moving forward? Patient 3(2): 79-89.

33. Louviere J, Hensher D, Swait J (2000) Stated Choice Methods: Analysis and Applications. Cambridge, UK: Cambridge University Press.

34.Viney R, Lancsar E, Louviere J (2002) Discrete choice experiments to measure consumer preferences for health and healthcare. Expert Rev Pharmacoecon Outcomes Res 2(4): 89-96.

35. Lancsar E, Louviere J (2008) Conducting discrete choice experiments to inform healthcare decision making: a user's guide. Pharmacoeconomics 26(8): 661-677.

36. Hensher DA, Rose JM, Greene WH (2005) Applied Choice Analysis: a Primer. Cambridge, UK: Cambridge University Press.

37. Ryan M, Farrar S (2000) Using conjoint analysis to elicit preferences for health care. BMJ 320(7248): 1530-1533.

38. Mühlbacher AC, Lincke HJ, Nübling M (2008) Evaluating patients' preferences for multiple myeloma therapy, a discrete-choice experiment. Psychosoc Med 5: Doc10.

39. Coast J, Salisbury C, de Berker D, Noble A, Horrocks S, et al. (2006) Preferences for aspects of a dermatology consultation. Br J Dermatol 155(2): 387-392.

40. Regier DA, Ryan M, Phimister E, Marra CA (2009) Bayesian and classical estimation of mixed logit: an application to genetic testing. J Health Econ 28(3); 598-610.

41. Wittink MN, Cary M, TenHave T, Baron J, Gallo JJ (2010) Towards patientcentered care for depression: conjoint methods to tailor treatment based on preferences. Patient 3(3): 145-157.

42. Hauber AB, Johnson FR, Mohamed AF, Leibman C, Arrighi HM, et al (2009) Older Americans' risk-benefit preferences for modifying the course of Alzheimer's disease. Alzheimer Dis Assoc Disord 23(1): 23-32.

43. Mohamed AF, Hauber AB, Johnson FR, Coon CD (2010) Patient preferences and linear scoring rules for patient reported outcomes. Patient 3(4): 217-227. 
44. Baker R, Bateman I, Donaldson C, Jones-Lee M, Lancsar E, et al. (2008) Weighting and valuing quality adjusted life years: preliminary results from the Social Value of a QALY project 14(7): 1-162.

45. Johnson FR, Özdemir S, Mansfield CA, Hass S, Miller DW, et al. (2007) Crohn's disease patients' benefit-risk preferences: serious adverse event risks versus treatment efficacy. Gastroenterology 133(3): 769-779.

46. Bridges J, Searle S, Selck F, et al. (2010) Engaging families in the design of social marketing strategies for male circumcision services in Johannesburg, South Africa. Soc Mar Q 16: 60-76.

47. Opuni M, Bishai D, Gray GE, McIntyre JA, Martinson NA (2010) Preferences for characteristics of antiretroviral therapy provision in Johannesburg, South Africa: results of a conjoint analysis. AIDS Behav 14(4): 807-815.

48. Fraenkel L (2008) Conjoint analysis at the individual patient level: issues to consider as we move from a research to a clinical tool. Patient 1(4): 251-253.
49. Nathan H, Bridges J, Schulick RD, Cameron AM, Hirose K, et al. (2011) Understanding surgical decision-making in early hepatocellular carcinoma. J Clin Oncol 29(6): 619-625.

50. Shumway M (2003) Preference weights for cost-outcome analyses of schizophrenia treatments: comparison of four stakeholder groups. Schizophr Bull 29(2): 257-266.

51. Ryan M (1999) Using conjoint analysis to take account of patient preferences and go beyond health outcomes: an application to in vitro fertilization. Soc Sci Med 48(4): 535-546.

52. Hanley GP, Iwata BA, McCord BE (2003) Functional analysis of problem behavior: a review. J Appl Behav Anal 36(2): 147-185. 